\title{
To Expand the Scope of Child Mental Health Professionals to Both Personal and Global Levels
}

\author{
Geon Ho Bahn \\ Editor-in-Chief, Korean Academy of Child and Adolescent Psychiatry
}

In the final of the 14th season of the America's Got Talent (AGT) show, aired on September 18, 2019, Kodi Lee was announced as the winner. Kodi, 23 years old, is blind and known to have autism spectrum disorder [1]. His behaviors and speech tone show the characteristics of autism. When he starts playing piano and singing, however, he falls deeply into the emotions corresponding to the lyrics of the song. He won AGT not just because of the advantage of being disabled, but because of his excellent talent for music. Watching Kodi singing reminded me of a lecture by Temple Grandin a few years ago. Despite her autistic traits, she captured the attention of several hundred people in the audience with her humor and coherent talk. The question arises if mental health experts in autism spectrum disorder can predict the potentials of young children suspected to have autism. Is it possible that diagnosis and treatment plans for mental disorders lets young autistic children's talents be stowed away in the storage room?

Two review articles in this volume cover young children with autism spectrum disorder: 'Review of early intervention for children with autism spectrum disorder: focused on randomized controlled trial' by Young-Hui Yang; and 'The use of artificial intelligence in screening and diagnosis of autism spectrum disorder: a literature review' by Da-Yea Song and Hee Jeong Yoo. There are also two original articles reporting on attention-deficit/hyperactivity disorder (ADHD) in this issue: Myung Ho Lim and his colleagues describe 'The relationship between the addiction of caffeinated drinks, burnout, and ADHD,' while Hyesoon Kim and Bongseog Kim present one issue of a series of research reports on juvenile inmates with ADHD using items from the Korean Youth Self Report. Another original article is Hyo-Won Kim et al.s 'Exploratory factor analysis of the Adolescent General Behavior Inventory in Korean youth.' The next original article investigates 'The effect of a community-based parent education program on parenting stress according to adult attachment style' by Na Ri Kang and Young Sook Kwack. In the book forum, Professor Un-Sun Chung reviewed Elisabeth Kübler-Ross' and David Kessler's book 'Life lessons: two experts on death and dying teach us about the mysteries of life and living.'

For this volume, we invited Dr Daniel Fung as a guest editor who kindly accepted our proposal. He is the current president of the International Association for Child and Adolescent Psychiatry and Allied Professionals (IACAPAP). The 24th World Congress of the IACAPAP will be held in Singapore on July 20-23, 2020. In his editorial, 'A journey to the East: Child Psychiatry in Asia' [2], he pointed out that the development of child psychiatry in the U.S. and European countries is relatively far more well developed compared to other regions. While some Asian and African countries have a much higher proportion of children among their total population than the U.S. and Europe, investment or development in pediatric psychiatry is low or delayed. There are also only few child mental health specialists in these countries. Daniel's editorial highlights the need for combined efforts of experts and the IACAPAP to reduce these inter-country and intercontinental differences.

The main goal of this academic journal publication is to share and discuss the clinical experience and knowledge of medical experts through papers and to ensure that patients are provided with the best quality of life. This journal from the Korean Academy of Child and Adolescent Psychiatry also strives to move forward the well-being of mentally challenged children and the members of their families in line with the aims of IACAPAP.

\section{REFERENCES}

1) kodileerocks.com. [cited 2019 Sep 25]. Available from URL: kodileerocks.com/.

2) Fung D, Lim-Ashworth N. A journey to the East: Child Psychiatry in Asia (editorial). J Korean Acad Child Adolesc Psychiatry 2019; 30(4):134-135. 